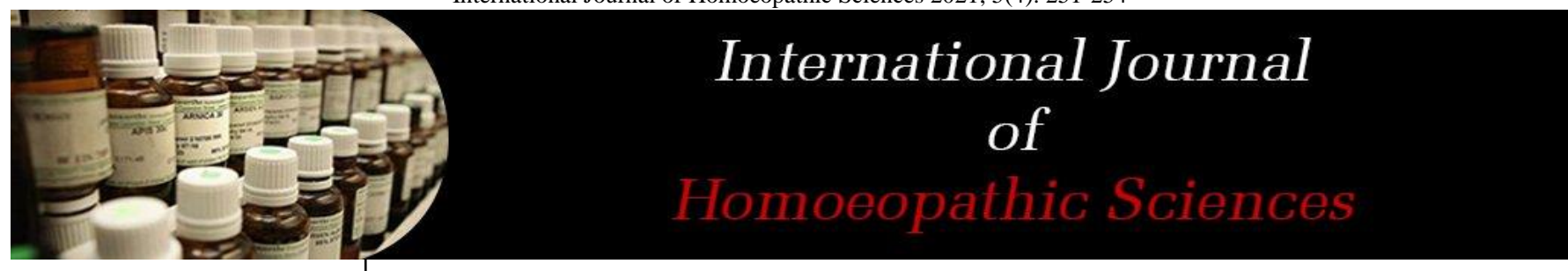

E-ISSN: $2616-4493$ P-ISSN: 2616-4485 www.homoeopathicjournal.com IJHS 2021; 5(4): 251-254 Received: 12-05-2021 Accepted: 23-07-2021

Dr. S Pavithra Post Graduate Student, Department of Repertory, Vinayaka Mission's Homoeopathic Medical College \& Hospital, A Constituent college of VMRF-Deemed to be University, Salem Tamil Nadu, India

Dr. J Senthil Kumar Professor, PG Guide, HOD, Department of Repertory, Vinayaka Mission's Homoeopathic Medical College \& Hospital, A Constituent College of VMRF-Deemed to be University, Salem, Tamil Nadu, India
Corresponding Author:

Dr. S Pavithra

Post Graduate Student, Department of Repertory, Vinayaka Mission's Homoeopathic Medical College \& Hospital, A Constituent college of VMRF-Deemed to be University, Salem,

Tamil Nadu, India

\section{Utility of a synoptic key of Materia medica by C.M. Boger in treating type II diabetes mellitus}

\author{
Dr. S Pavithra and Dr. J Senthil Kumar
}

DOI: https://doi.org/10.33545/26164485.2021.v5.i4d.481

\begin{abstract}
The chronic metabolic disorder diabetes mellitus is a fast-growing global problem with huge social, health, and economic consequences. It is estimated that in 2010 there were globally 285 million people (approximately $6.4 \%$ of the adult population) suffering from this disease. This number is estimated to increase to 430 million in the absence of better control or cure. An ageing population and obesity are two main reasons for the increase. Furthermore it has been shown that almost $50 \%$ of the putative diabetics are not diagnosed until 10 years after onset of the disease, hence the real prevalence of global diabetes must be astronomically high. Diabetes mellitus is a multifactorial disease that requires longterm care since it involves major changes in both physical and psychosocial dimension of each patient. Diabetes education is a critical element of care that improves patient outcomes.
\end{abstract}

Keywords: Diabetes mellitus (DM), Boger synoptic key (BSK) homoeopathy

\section{Introduction}

Globally, in the past three decades, the number of population with diabetes mellitus has multiplied enormously, and diabetes mellitus is the major cause of death. Every 1 in 11 adults worldwide now suffers from diabetes mellitus. Among those population 90 percentage of whom have diagnosed with type II diabetes mellitus. (T2DM) ${ }^{[1]}$

Currently over 49 percentage of the world's diabetes mellitus burden represents by India, with approximately 72 million cases in 2017, and it is expected to almost double upto 134 million by $2025^{[2]}$. According to the American diabetes association in 1997, defines diabetes mellitus as a group of metabolic disorders leading to defects in action of insulin and insulin resistance or both ${ }^{[3]}$.

Diabetic patients, if undiagnosed or inadequately treated, develop multiple complications which leads to irreversible disability and even death in severe cases. Coronary artery disease and stroke are more common in diabetic patients than in the general population ${ }^{[9]}$.

\section{Diabetes mellitus}

"Diabetes mellitus is a syndrome, which is clinically characterized by increased level of plasma blood glucose (hyperglycaemia). Type 2 diabetes mellitus is characterized by the resistance to action of insulin and an inability to produce sufficient insulin to overcome the 'insulin resistance'. Less severe case of hyperglycaemia is known as 'impaired glucose tolerance'. Hyperglycaemia may leads to both acute and chronic illness" [4]

Diabetes mellitus is a chronic disease caused due to disordered carbohydrate metabolism and results from insulin deficiency and it is clinically presented by hyperglycaemia and glycosuria, with secondary derangement in the lipid metabolism. Usually the person will become ill within 15 to 25 years of onset of the disease.

\section{Epidemology}

\section{World Wide}

In many countries, type 2 diabetes mellitus has already reached the epidemic proportions, due to its increasing prevalence globally. The international diabetes federation's recent estimation shows that approximately 366 million adults were affected by this disease in 2011 and which was expected to be increased up to 552 million by 2030 . In middle and low income countries nearly $80 \%$ of population were estimated to be affected ${ }^{[8]}$ 
Among the top countries/ territories with the largest number of diabetic adults, five are in Asia. China, leads the list with 90.0 million followed by India with 61.3 million people are affected by diabetes. The numbers are estimated to rise to 129.7 million and 101.2 million, respectively by $2030^{[8,6]}$.

\section{In India}

India is currently an epidemic of diabetes mellitus. According to world health organization, India is the country with large number of diabetic cases in world. More than 8590 percentage of all patients with DM are suffering from type II diabetes mellitus. In adults the prevalence of DM is increasing worldwide. The prevalence of diabetes in urban areas -2.1 percentage and in rural areas 1.5 percentage ${ }^{[6]}$. In another $20-25$ years the $1 / 5$ th of the world's population will be from India ${ }^{[8]}$.

According to current statement by IDF, almost 3.0 percentage of adults in India present with pre-diabetes. In Indian diabetic prevention programme-1, a prospective study shows, high conversion rate of diabetes by 17-18 percent per year ${ }^{[8]}$.

\section{Symptoms of diabetes mellitus Acute presentation}

Young adults present with the classic triad of symptoms.

- Polyuria - due to osmotic diuresis

- Polydipsia - due to loss of electrolytes and fluids

- Weight loss - due to fluid depletion and breakdown of lipids and muscles.

Patient often present with ketonuria which may progress to ketoacidosis if the early symptoms are not treated and ignored ${ }^{[10]}$.

\section{Subacute presentation}

The clinical onset of symptoms may develop over several months or years. Polydipsia, polyuria and weight loss are typically present, but major patient complains of lack of energy, blurred vision, pruritus vulvae or balanitis due to candida infection ${ }^{[10]}$.

\section{Physical examination at diagnosis}

Visible weight loss and dehydration, breath may smells of ketones. Older patients present with established complications like retinopathy. Insulin resistance patients may have acanthosis nigricans, characterized by blackish pigmentation at nape of neck and axillae ${ }^{[10]}$.

\section{Objectives of the study}

- To study the utility of synoptic key of materia medica by C.M.Boger.

- To assess the efficacy of Homoeopathic medicines in treating type II diabetes mellitus.

The patient will be reviewed for once in 15days for next one year basing on the particular case. Sample size will be 30 in number.

\section{Materials and methods source of data}

Patients will be collected from the outpatient department, inpatient department, Peripheral health centres of Vinayaka Mission's Homoeopathic Medical college \& Hospital,
Salem \& Medical camps conducted by the homoeopathic institution of Vinayaka mission's. The literature will be collected from authentic textbooks and journals.

\section{Inclusion criteria}

Male and Female patients of age group between 25-65years of age with classical symptoms of type II diabetes mellitus.

\section{Exclusion criteria}

Patients under any other systemic illness and long standing anti-diabetic treatment. Cases under any other chronic medications \& cases with established complications. Patients above the age group of 65 years.

\section{Treatment plan}

The patients were assessed, analyzed and evaluated according to Boger's method. Repertorization was done using Boger Synoptic Key repertory. Miasmatic interpretation was done by using the presenting complaints, past history, family history, mental and physical generals.

Pathological generals, Clinical rubrics, Concomittants, physical generals and Modalities were considered for the selection of the remedy. Criteria for follow up were Pathological generals, Clinical rubrics, Concomittants, physical generals and Modalities

\section{Observations and results}

Table 1: Distribution of cases in my study of type II DM according to the gender

\begin{tabular}{|c|c|c|c|}
\hline SL. NO & Gender & No of patients & Percentage \\
\hline 1. & FEMALE & 09 & $30 \%$ \\
\hline 2. & MALE & 21 & $70 \%$ \\
\hline
\end{tabular}

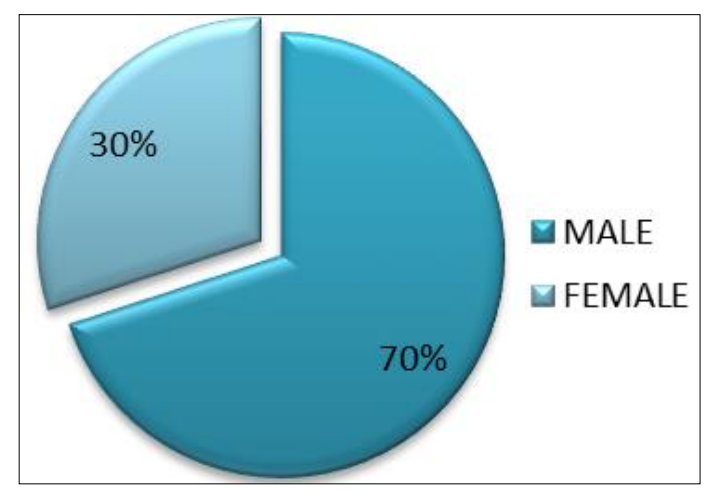

Fig 1: Distribution according to gender

According to my study on the type II diabetes mellitus, $30 \%$ (9 cases) were females and 70\% (21 cases) were males.

Table 2: Distribution of cases in my study of type II DM according to the age

\begin{tabular}{|c|c|c|c|}
\hline Sl. No. & Age (in years) & No of Caeses & Percentage \\
\hline 1. & $25-35$ & 05 & $17 \%$ \\
\hline 2. & $36-45$ & 15 & $50 \%$ \\
\hline 3. & $46-55$ & 09 & $30 \%$ \\
\hline 4. & $56-65$ & 01 & $3 \%$ \\
\hline
\end{tabular}




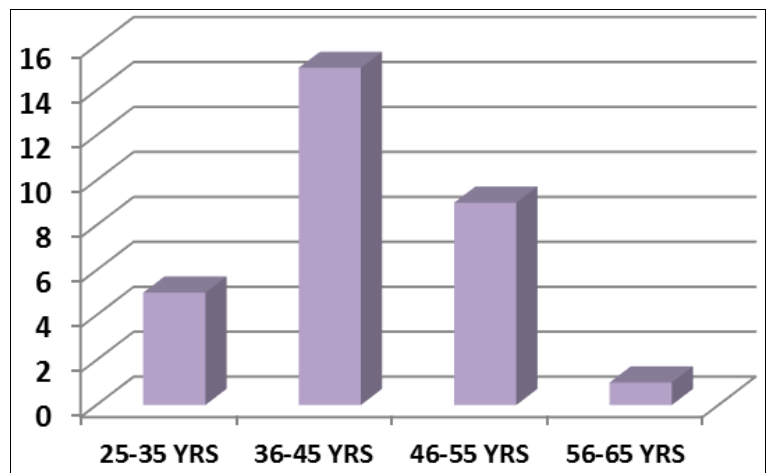

Fig 2: Distribution of cases according to age

According to my study on type II diabetes mellitus, $17 \%$ of patients are under the age group of 25-35 years of age, 50\% of patients are under the age group of 36-45 years of age, $30 \%$ of patients are under the age group of 46-55 years of age, $3 \%$ of patients are under the age group of 56-65 years of age.

Table 3: Distribution of cases in my study of type II DM according to the family history of DM

\begin{tabular}{|c|c|c|c|}
\hline Sl. No. & Family history of DM & No. Of patients & Percentage \\
\hline 1. & Father & 06 & $20 \%$ \\
\hline 2. & Mother & 10 & $33.3 \%$ \\
\hline 3. & Both father \& mother & 07 & $23.3 \%$ \\
\hline 4. & Sister / brother & 03 & $10.4 \%$ \\
\hline 5. & No family history of diabetes & 04 & $13 \%$ \\
\hline
\end{tabular}

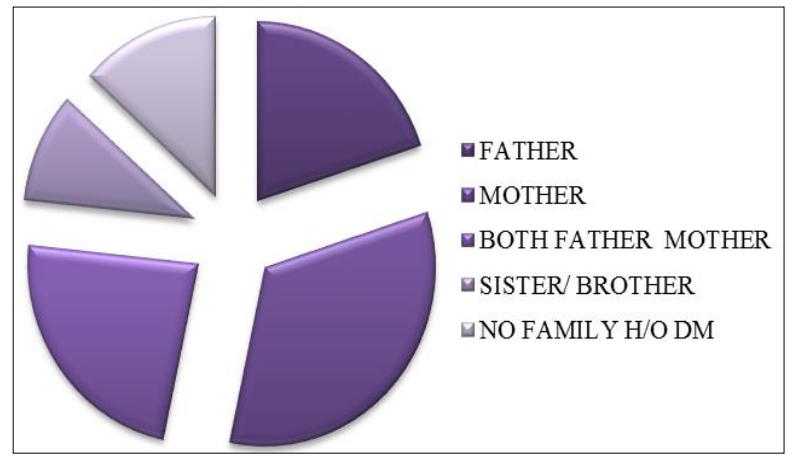

Fig 3: Distribution of cases according to family history of diabetes mellitus

According to my study on type II DM, 20\% of patient's fathers have history of diabetic, $33.3 \%$ of patient's mothers have history of diabetic, $23.3 \%$ of patient's both fathers and mothers have history of diabetic, $10.4 \%$ of patient's brothers or sisters have history of diabetic and $13 \%$ of patient have no any relevant family history of Diabetes mellitus.

Table 4: Distribution of cases in my study according to the symptoms of type II dm

\begin{tabular}{|c|c|c|c|}
\hline Sl. No. & Symptoms & No. Of patients & Percentage \\
\hline 1. & POLYDYPSIA & 24 & $80 \%$ \\
\hline 2. & FATIGUE & 18 & $60 \%$ \\
\hline 3. & POLYPHAGIA & 17 & $56 \%$ \\
\hline 4. & POLYURIA & 13 & $43.3 \%$ \\
\hline 5. & WEIGHT LOSS & 03 & $10 \%$ \\
\hline 6. & ASYMPTOMATIC & 02 & $6.66 \%$ \\
\hline
\end{tabular}

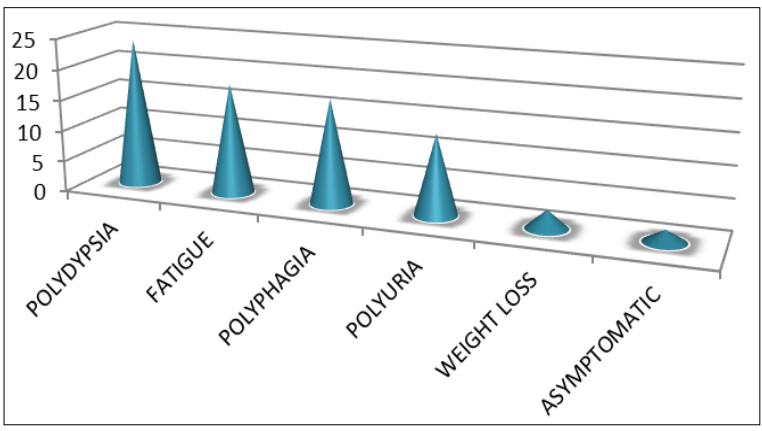

Fig 4: Distribution of cases according to the symptoms of type ii $\mathrm{DM}$

According to my study on type II DM, (24)80\% cases had polydipsia, (18)60\% cases had fatigue, (17)56\% cases had polyphagia, (13) $43.3 \%$ cases had polyuria, and (3)10\% cases had gradual weight loss, (2)6.66\% cases without symptoms of type II diabetes mellitus.

Table 5: Distribution of cases in my study of type II dm according to the remedy selected

\begin{tabular}{|c|c|c|c|}
\hline SL. No & Remedy & No of cases & Percentage \\
\hline 1. & Arsenicum Album & 04 & $13.33 \%$ \\
\hline 2. & Lycopodium & 02 & $6.7 \%$ \\
\hline 3. & Natrum Muriatium & 04 & $13.33 \%$ \\
\hline 4. & Nux Vomica & 03 & $10 \%$ \\
\hline 5. & Phosphoric Acid & 02 & $6.7 \%$ \\
\hline 6. & Phosphorus & 03 & $10 \%$ \\
\hline 7. & Sepia & 02 & $6.7 \%$ \\
\hline 8. & Sulphur & 10 & $33.3 \%$ \\
\hline
\end{tabular}

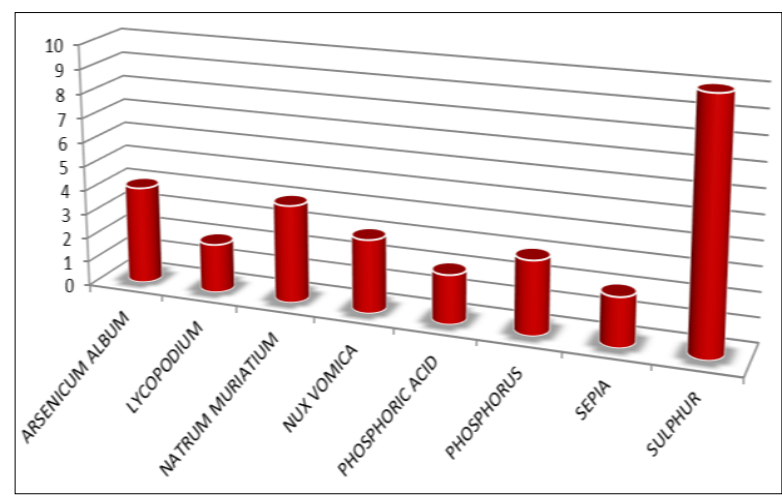

Fig 5: Distribution of remedy

According to my study on type II DM, (4)13.33\% of cases are treated with arsenicum album, (2)6.7\% of cases are treated with lycopodium, (4)13.33\% of cases are treated with natrum muriaticum, (3)10\% of cases are treated with nuxvomica, (2) $6.7 \%$ of cases are treated with phosphoric acid, (3)10\% of cases are treated with phosphorus, (2)6.7\% of cases are treated with sepia, (10)33.3\% of cases are treated with Sulphur.

Table 6: Distribution of cases in my study of type II dm according to the improvement after treatment

\begin{tabular}{|c|c|c|c|}
\hline Sl. No. & Improvement & No of Caeses & Percentage \\
\hline 1. & Marked Improvement & 13 & $43 \%$ \\
\hline 2. & Moderate Improvemet & 15 & $50 \%$ \\
\hline 3. & No Improvement & 02 & $07 \%$ \\
\hline
\end{tabular}




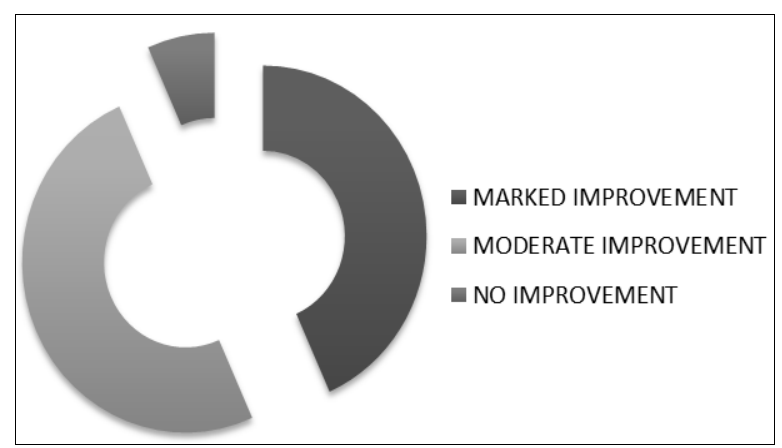

Fig 6: Distribution of cases according to improvement in hbalc values

According to my study on type II DM, 13 (43\%) cases have marked improvement in HbA1c value, 15 (50\%) cases have moderate improvement in HbA1c value, and $02(07 \%)$ cases have no improvement in $\mathrm{HbA} 1 \mathrm{c}$ value.

\section{Summary and Conclusion}

Homoeopathic system with its individualistic approach and unique principles treat the suffering humanity as a whole. Homoeopathy with its time honored clinical trials and results shown its effectiveness in various clinical conditions such as type II diabetes mellitus.

Keeping this in prior, the study was conducted and Randomly 30 cases of type II diabetes mellitus were selected for the consideration of my study. The study population of the patients were between the age group of 25 - 65 years. All the details of the patients were taken with proper clinical examination and case taking. The similimum was administered to all the patients based on the repertorization in order to assess the utility of A Synoptic key of materia medica by C.M. Boger in treating type II diabetes mellitus.

In my study

- Type II diabetes mellitus commonly affected the age group between $36-45$ years of age.

- Occupational histories revealed that most affected were coolies.

- Majority of the cases were having the family history of diabetes mellitus.

- The majority of the cases had got marked improvement from the complaint.

- Out of 30 cases, $13(43 \%)$ cases have marked improvement in $\mathrm{HbA} 1 \mathrm{c}$ value, $15(50 \%)$ cases have moderate improvement in $\mathrm{HbA} 1 \mathrm{c}$ value, and $02(07 \%)$ cases have no improvement in HbA1c value.

- This proves that, the utility of A Synoptic key of materia medica by C.M. Boger is more effective.

- This shows that, the selected similimum can effectively reduce the HbAlc levels in the patients with type II diabetes mellitus.

This shows that utility of A synoptic key of materia medica by C.M. Boger in treating type II diabetes mellitus is highly effective and useful.

A course of one year study shows that homoeopathic medicines selected using A Synoptic key of materia medica by C.M. Boger by the process of repertorization can effectively reduce the HbAlc levels in the patients with post-treatment HbA1c levels in between $6.5 \%-8.0 \%$. this study also facilitates better understanding of type II diabetes mellitus and dietary management. As type II diabetes mellitus is a lifestyle disorder, co-operation from the patient in dietary and lifestyle intervention is mandatory.

\section{References}

1. https://www.ncbi.nlm.nih.gov/pubmed/29219149)

2. https://www.firstpost.com/india/diabetes-is-indiasfastest-growing-disease-72-million-cases - recorded-in2017-figure-expected-to-nearly-double-by-20254435203.html)

3. Chawla Rajeev. Manual of diabetes care. New Delhi, Jaypee brother's medical publisher (p)ltd, 2014, 1p

4. Brian R Walker, Nicki R Colledge, Stuart H Penman. Davidson's principles and practice of medicine, $22^{\text {nd }}$ edition, Churchill livingstone Elsevier, edinburg, London, New York, Oxford, Philadelphia, St louis Sydney, Toronto, 2014, 800-834.

5. Dey NC, Dey TK. A Text book of Pathology, edition new central book agency, 1996, 11.16-11.19

6. Das AK, Rao PV, Madhu SV, Mohan V, Rssdi Text book of Diabetes mellitus, $2^{\text {nd }}$ edition, Jaypee; $1: 163,164,165$.

7. Maxine A Papadaris, Stephen J Mcphee, Michael W Rabow. Current Medical Diagnosis and treatment Mc Graw Hill education Lange 2019, 1220, 1221, 1222.

8. Muruganantham A. Medicine Update, volume 23, association of physicians India, 2013, 1102.

9. Park-Banarsidas K. Bhanot, Park's Textbook of Preventive and Social Medicine, 23rd Edition, Bhanot; 399

10. Harsh Mohan, Textbook of Pathology, seventh edition, foreword Ivan Damjanov, 808.809,810,811,812,816. 